\title{
What is the role of video-assisted thoracoscopy for patent ductus arteriosus ligation in the era of transcatheter closure?
}

\author{
Alain Fraisse ${ }^{1,2}$, Guido Michielon ${ }^{2,3}$, Aleksander Kempny ${ }^{2,4}$ \\ ${ }^{1}$ Paediatric Cardiology Services, Royal Brompton Hospital and Harefield NHS Foundation Trust, London, UK; ${ }^{2}$ National Heart and Lung Institute, \\ Imperial College London, London, UK; ${ }^{3}$ Congenital Cardiac Surgery Service, ${ }^{4}$ Adult Congenital Heart Disease Unit, Royal Brompton Hospital and \\ Harefield NHS Foundation Trust, London, UK \\ Correspondence to: Alain Fraisse. Paediatric Cardiology Services, Royal Brompton Hospital and Harefield NHS Foundation Trust, Sydney Street, SW3 \\ 6NP London, UK. Email: a.fraisse@rbht.nhs.uk. \\ Provenance: This is an invited article commissioned by the Editorial Office, Fournal of Thoracic Disease. \\ Comment on: Stankowski T, Aboul-Hassan SS, Seifi-Zinab F, et al. Descriptive review of patent ductus arteriosus ligation by video-assisted \\ thoracoscopy in pediatric population: 7-year experience. J Thorac Dis 2019;11:2555-63.
}

Submitted Aug 31, 2019. Accepted for publication Sep 29, 2019.

doi: $10.21037 /$ jtd.2019.10.08

View this article at: http://dx.doi.org/10.21037/jtd.2019.10.08

In a recent issue of the Journal, Stankowski et al. (1) report their single centre experience of 7 years of patent ductus arteriosus ligation using video-assisted thoracoscopy (VATS) in paediatric population. They studied 127 patients between 2012 and 18, including $38.6 \%$ preterm infants. There was no surgical mortality but 6 patients (4.7\%) died during in-hospital stay, predominantly in the neonatal intensive care unit (NICU) due to cerebral haemorrhage and cardiopulmonary failure. The conversion rate to thoracotomy was $16.5 \%$ (5\% in late phase from 2015-2018). Fifty patients (39.4\%) were transferred to the NICU. The mean in-hospital stay for the remainders was $2.2 \pm 1.6$ days. The 5 -year probability of survival estimated according to the Kaplan-Meier curve was 93.6\%. The authors concluded that VATS is a safe and efficient method for PDA ligation that also ensures satisfactory late cosmetic results. They consider that their postoperative mortality and extended hospital stay may be attributed to prematurity (1).

The authors should be congratulated for the accuracy of their published data. Especially, they rigorously describe the increased morbidity during their learning curve, corresponding to an early phase of 73 patients between 2012 and 2014. During this period, $17.8 \%$ of the cases were converted to a thoracotomy. Such a long learning curve clearly represents a limit to the widespread diffusion of VATS, especially because the vast majority of the centres will not perform such number of cases within a $2-3$ years period.

One important question is whether or not transcatheter closure was an alternative for their study patients. Stankowski et al. state in the Method section that "none of them was an appropriate candidate for percutaneous closure". We wonder if this statement is accurate. Even if they included 47 patients (36\%) weighting less than $2.5 \mathrm{~kg}$, it is surprising that in a tertiary centre with a modern program of transcatheter intervention, up to 80 patients during a period of 6 years would escape the catheterisation laboratory to undergo surgery. With only $28.3 \%$ of the patients being in cardiac failure and a mean diameter of the PDAs of $3.9 \pm 1.3 \mathrm{~mm}$, it is difficult to imagine that cases with such characteristics were all contraindicated for any catheter intervention. It would have then been interesting to know if in some of their study patients transcatheter closure was attempted and failed.

In the current era, less invasive transcatheter PDA occlusion is the first intention treatment for most PDAs in term infants, children and adults. The vast majority of patients are usually suitable and recent studies have demonstrated safety and effectiveness, also in premature babies $(2,3)$. Interestingly, no randomized studies have been performed to definitely confirm that transcatheter closure should be the first intention treatment for PDA closure. In 1993, the results of a cohort study comparing device closure and surgical ligation were clearly in favour 
of surgery. The authors concluded that "more effective and less costly surgical procedure was superior to transcatheter placement of the occluder for closure of isolated patent ductus arteriosus" (4). Yet, this was before the era of the Amplatzer devices. More recently, a 20 years meta-analysis concluded that both treatments have comparable outcomes with more reinterventions after transcatheter closure but not surprisingly a shorter hospital stay (5). Nevertheless, multicentre studies on transcatheter PDA closure performed in the current era demonstrated an extremely low rate of failure and only $2 \%$ of adverse events (6).

Despite the excellent results of Stankowski's study, VATS will not become the first intention technique for PDA closure. Transcatheter closure is and will continue to be performed as first intention treatment. Of course, support of surgical teams to cover such interventional program is crucial and surgery will remain the only possibility to close a minority of PDA that are not suitable for device closure. Consequently, in the majority of the centres with large volume of transcatheter PDA closure the number of surgical cases may not exceed 5 per year. In such centres the learning curve for VATS, based on the volume of the early phase published by Stankowski et al., would potentially be more than one decade. Although any less invasive surgical technique, such as VATS, should be strongly encouraged, future studies may help to clarify whether or not a VATS program can be realistically organised in the setting of low volume surgical cases.

\section{Acknowledgments}

None.

\section{Footnote}

Conflicts of Interest: A Fraisse is consultant and proctor for
Abbott and for Occlutech. The other authors have no conflicts of interest to declare.

Ethical Statement: The authors are accountable for all aspects of the work in ensuring that questions related to the accuracy or integrity of any part of the work are appropriately investigated and resolved.

\section{References}

1. Stankowski T, Aboul-Hassan SS, Seifi-Zinab F, et al. Descriptive review of patent ductus arteriosus ligation by video-assisted thoracoscopy in pediatric population: 7-year experience. J Thorac Dis 2019;11:2555-63.

2. Morville P, Akhavi A. Transcatheter Closure of Hemodynamic Significant Patent Ductus Arteriosus in 32 Premature Infants by Amplatzer Ductal Occluder Additional Size-ADOIIAS. Catheter Cardiovasc Interv 2017;90:612-7.

3. Sathanandam S, Balduf K, Chilakala S, et al. Role of Transcatheter patent ductus arteriosus closure in extremely low birth weight infants. Catheter Cardiovasc Interv 2019;93:89-96.

4. Gray DT, Fyler DC, Walker AM, et al. Clinical outcomes and costs of transcatheter as compared with surgical closure of patent ductus arteriosus. The Patient Ductus Arteriosus Closure Comparative Study Group. N Engl J Med 1993;329:1517-23.

5. Lam JY, Lopushinsky SR, Ma IWY, et al. Treatment Options for Pediatric Patent Ductus Arteriosus: Systematic Review and Meta-analysis. Chest 2015;148:784-93.

6. El-Said HG, Bratincsak A, Foerster SR, et al. Safety of percutaneous patent ductus arteriosus closure: an unselected multicenter population experience. J Am Heart Assoc 2013;2:e000424.
Cite this article as: Fraisse A, Michielon G, Kempny A. What is the role of video-assisted thoracoscopy for patent ductus arteriosus ligation in the era of transcatheter closure? J Thorac Dis 2019;11(10):4090-4091. doi: 10.21037/jtd.2019.10.08 